\title{
Early Recurrent Inversion - A Case Report
}

\author{
NAZNEEN KABIR ${ }^{1}$, FERDOUSI ISLAM ${ }^{2}$, FATEMATUL ZANNAT ${ }^{3}$, MOLLIKA RAZZAK $^{3}$
}

\section{Introduction:}

Uterine inversion is an unusual entity ${ }^{1-4}$. It is encountered as an obstetric emergency and a diagnostic challenge in gynecology. Uterine inversion is the prolapse of the fundus to or through the cervix so that the uterus is in effect turned inside out. In a full uterine inversion, the uterus may be visible inside the vagina. Inversion of the uterus may be classified as puerperal or obstetric and non puerperal or gynecologic. Acute puerperal inversion is also classified into three types according to severity. In incomplete inversion no part of the body of the uterus extends beyond the cervix. When the inverted fundus extends beyond the cervix but not beyond the introitus it is designated as complete inversion. It is classified as prolapsed inversion when the inverted fundus extends beyond the introitus ${ }^{5}$. Puerperal inversion is uncommon but life threatening obstetric emergency. It is the dangerous complication of the third stage of labour ${ }^{6}$ and occurs in 1 in 20,000 deliveries ${ }^{7}$ (frequently cited). It is more common in primipara and may recur in subsequent pregnancy in $25 \%$ of cases $^{5}$. Though frequently cited incidence was 1 in 20,000, other reported incidence vary from 1 in 4000 to 1 in 100,000 deliveries or lower. In Dhaka Medical College Hospital (DMCH), hospital incidence was 1 in 1276 (1991-1992) and in Karachi, Pakistan, the hospital incidence was 1 in 1584 deliveries (1995-2002) 8,9.

Recurrent inversion is very rare. A case of early recurrence of uterine inversion (Re-inversion) is presented here.

\section{Case Summary}

A 25-year old woman ( para 1) was admitted within six hours of delivery into the hospital because of postpartum hemorrhage and shock. She was pale, her pulse rate was $120 / \mathrm{min}$ and blood pressure was $70 / 40 \mathrm{mmHg}$. On abdominal examination, fundus of uterus was not found in the lower abdomen; rather a dark red-blue bleeding mass without placenta was seen in the vagina encircled by the cervix. After opening the intravenous line two bags of whole blood were transfused. Manual reposition was attempted immediately after resuscitation of the patient. The inverted uterus was gradually and continuously replaced by squeezing the uterus in hand beginning from last inverted part under general anesthesia. The fundus was replaced lastly ${ }^{10}$. After repositioning the uterus, the hand was kept inside the endometrial cavity until a firm contraction occurred. Intravenous oxytocin was given instantaneously to prevent recurrence following vaginal packing and catheterization. The condition of the patient improved as evidenced by the observation of blood pressure $(90 / 60 \mathrm{mmHg})$ and pulse rate $(84 / \mathrm{min})$ after reposition. The patient was transfused for the third time with another whole blood to combat anemia and to ensure sustained haemodynamic stable status. However, the patient was kept under intense half hourly follow up for next six hours of post reposition. Then hourly follow up was continued for another twenty four hours. Catheter and vaginal pack were removed after 24 hours.

The patient developed retention of urine on fifth postoperative day. Uterus was at the level of pubic symphysis at that time. Catheterization was done again. On the following day, uterus could not be palpated per abdominally. Per speculum examination confirmed uterine reinversion. Cervical ring was found constricted at that time and the decision was taken in favor of operative treatment.

Sub acute inversion of this patient was corrected by Haultains operation where constricted cervical ring was incised per abdominally. Surgical intervention is usually mandatory in sub acute or chronic cases ${ }^{11}$. After opening the abdomen constriction ring was incised from posterior aspect up to vagina. Inverted uterus was pushed back through the opening made in the posterior vaginal wall by placing a finger into the vagina. After reposition, the wounds in the uterus, cervix and vagina were repaired with interrupted suture 12. Plication of round ligament was done afterwards

1. Associate Professor.

2. Professor.

3. Assistant Registrar

Faculty of OBGYN, Institute of Child and Mother Health (ICMH) 
to maintain ante version of the uterus. Subsequent post operative period was uneventful and the patient recovered smoothly. She was discharged after seven days of operation and advised to turn on follow up.

\section{Discussion}

Most cases of uterine inversion are puerperal and acute. Non puerperal inversions are extremely rare and are usually chronic but $8.6 \%$ are presented as of sudden onset ${ }^{13}$. It occurs chiefly when the uterus acts to expel a submucous leiomyoma with fundal attachment ${ }^{14,15}$. Acute puerperal inversion of uterus is also a rare but potentially fatal complication of the third stage of labor. Predisposing factors for inversions are fundal implantation of placenta, adherent placenta and uterine atony. A slight dimpling of the thinned out uterine wall beneath the placental site rapidly progresses to inversion with each uterine contraction. This may be enhanced by maneuvers like fundal pressure or cord traction especially in the presence of short $\operatorname{cord}^{7}$. Complications of inversion are hemorrhage and shock ${ }^{16}$. Shock is mainly neurogenic due to stretch of the nerves in the infundibulopelvic ligaments and ovarian ligaments. During the period from 1991 to 1992 all patients of uterine inversions admitted in Dhaka Medical College Hospital (DMCH) presented with profound shock ${ }^{8}$. Majority of the patients of Jinnah Postgraduate Medical Centre of Pakistan also presented with shock either hypovolemic $(69 \%)$ or neurogenic (13\%) in origin. Mismanagement of third stage of labor was found responsible for uterine inversion in $75 \%$ of patients ${ }^{9}$.

This patient developed complete inversion (fundus prolapsed through the cervix) after delivering the placenta. Her shock was of both hypovolemic and neurogenic in origin. Puerperal inversion is more common (95\%) than non puerperal $(5 \%)^{7}$. Inversion may be acute, sub acute or chronic. This patient is an example of two verities of inversion i.e she developed sub acute inversion after correction of acute inversion. In Nepal $2.62 \%$ cases of inversion were of sub acute varity ${ }^{17}$. This patient also may be described as early recurrent inversion because she developed urinary retention after correction of acute inversion. The presentation of symptoms of constipation and urinary retention without having uterine bleeding is a usual finding in case of delayed uterine re-inversion ${ }^{18}$. Sometimes patients may be misdiagnosed as uterine myoma of malignant type ${ }^{19}$. The only reported case of uterine inversion secondary to alveolar rhabdomyosarcoma of the uterus was diagnosed during total abdominal hysterectomy (TAH) ${ }^{20}$.

The etiology of inversion is not always very clear. Fetal macrosomia is also a risk factor along with other risk factors already mentioned like primi parity and fundal implantation of placenta ${ }^{21}$. Uterine inversion is more common when cord traction is used for delivery of the placenta without effective guarding of the uterus, and when the uterus is lax.

The controlled cord traction for delivery of the placenta reduces the risk of uterine inversion. If fundal insertion of placenta could be diagnosed by ultrasonography before delivery, the woman should be delivered by trained birth attendant or in a well equipped hospital. If inversion occurs, it should be corrected successfully with prompt intervention in acute case. Treatment relies on reduction of the inversion, which should take place as early as possible and prevention of a relapse ${ }^{22}$. Delay in treatment of acute uterine inversion causes dense constriction ring formation, progressive edema, hemorrhage and tissue necrosis and subsequently, the uterus cannot be repositioned by vaginal manipulation. If the initial attempt fails, laparotomy is imperative because the constriction ring prohibits reposition. The constricted ring is carefully incised from the posterior end to expose the fundus. The uterus is repositioned by pulling from above ${ }^{12}$. Inversion of uterus can be treated by vaginal operation where pouch of Douglas is opened by giving incision in posterior vaginal wall (Kustner's method). Subsequently, the whole thickness of uterus and cervix is cut through and the fundus of the uterus is pushed upwards through the cervix holding the cut edges with volsellum forceps and the inversion is corrected ${ }^{12}$.

All cases of inversion should be followed up closely for one week and throughout puerperium for early detection of reinversion. Urinary retention after correction of inversion should be immediately evaluated.

\section{References}

1. Aspevik RK, Haffner J. Pureperal inversion of the uterus (in Norwegian). Tidsskr Nor Laegeforen. 1989;109: 1403-1404.

2. Grischke EM, Wallwiener D, Bastert G. Puerperal uterine inversion with covered uterine rupture (in German). Z Geburtshilfe Neonatol. 1999;203:123-125. 
3. Salomon CG, Patek SK. Computed tomography of chronic non puerperal uterine inversion. J ComputAssist Tomogr. 1990; 14: 1024-1026.

4. Tews G, Ebner T, Yaman C, Sommergruber M, Bohaumilitzky T. Acute puerperal inversion of the uterus-treatment by a new abdominal uterus preserving approach. Acta Obstet Gynecol Scand. 2001;80:1039-1040.

5. Usha Krishna, D.K Tank, Shirish Daftary, Pregnancy at Risk Current Concepts. A FOGSI publication JAYPEE Brothers, Medical publishers (P) Ltd. New Delhi 2001. Forth ed, P-462

6. Tank Parikshit D, Mayadeo Niranjan M, Nanddanwar YS. Pregnancy outcome after operative correction of puerperal uterine inversion. Arch Gynecol Obstet. 2004 Mar; 269(3):214-6.

7. Alan H. DeCherney, Lauren Nathan. Current Obstetric \& Gynaecologic Diagnosis \& Treatment. $9^{\text {th }}$ edition, 2003; Lange Medical BooksIMcGraw-Hill: 539-540

8. Saleh Mahmud Jahangir, Iffat Ara. Acute puerperal inversion of the uterus. J Dhaka Med Coll 1992; 2(1): 5-7

9. Hussain $\mathrm{M}$, Jabeen $\mathrm{T}$, Liaquat $\mathrm{N}$, Noorani $\mathrm{K}$, Bhutta SZ. Acute puerperal uterine inversion. J Coll Physicians Surg Pak. 2004 Apr; 14(4): 215-7.

10. D Keith Edmonds, Dewhurst's textbook of Obstetrics and Gynaecology for Postgraduates. Blackwell Science Itd. 1999 P-320

11. Brar HS, Greanspoon JS, Platt LD, Pual Rh. Acute puerperal inversion. New approach to management. J Reprod Med 1989; 134:173-177.

12. Christopher N Hudson, Marcus E Setchell, Shaws Textbook of Operative Gynaecology $6^{\text {th }}$ edition 2001. ELSEVIER a division of Reed Elsevier India Private Limited. New Delhi India : 110-111
13. Taherh Ashraf-Ganjooie. Nonpuerperal uterine inversion - a case report. Archives of Iranian Medicine, 2005; I8(1):63-66

14. Barhmi R, Ferhati D, Nabil S, et al. Complete non obstetrical uterine inversion, J Gynecol Obstet Bial Reprod. 1995;24: 155-57.

15. Lai FM, Tseng P, Yeas SH, Tsakok FH. Non puerperal uterine inversion - a case report. Singapore Med J, 1993;34:466-468.

16. Bijoy Sree Senghpta, Sisir K Chatto padhyay, Jones G Thorution, Partha Sarathi Sengupta. Obstetrics for Post Graduate and Practitioners . Aspects of fetal \& maternal medicine. BI. Churchill Livingstone 1999, P-473-474.

17. Dali SM, Rafbhandari S, Shrestha S. Puerperal inversion of the uterus in Nepal,: case reports and review of literature. J Obstet Gynaecol Res. 1997 June; 23(3):319-25.

18. Silver DF, Heyl PS, Linfert JB. Delayed uterine re-inversion: a unique symptom complex. Am J Obstet Gyneacol, 2004 Jul; 191 (1): 378-9.

19. Has R, Ibrahimoglu L, Ozgun T, Turker A. Chronic uterine inversion: preservation of the uterus-case report. Clin Exp Obstet Gynecol. 2004; 31(4):313-5.

20. Case AS, Kirby TO, Conner MG, Huh WK. A case report of rhabdomyosarcoma of the uterus associated with uterine inversion. J Gynecol Oncol 2005 Mar; 96(3): 850-3.

21. Craigo SD, Kapernick PS. Postpatum hemorrhage and the abnormal peurperium. In: Decherney $\mathrm{AH}$, Pernoll ML, eds. Current Obstetric and Gynecologic Diagnosis and Treatment. $7^{\text {th }}$ ed. East Norwalk: Appleton and Lange; 1991:574-593.

22. Jerbi M, Iraqui $Y$, Jacob D, Truc JB. Puerperal uterine inversion: about two cases. Gynecol Obstet Fertil. 2004 Mar; 32(3): 224-7. 